\title{
Long-Term Results of stereotactic Brachytherapy (Temporary 125Iodine Seeds) for the Treatment of Low-Grade Astrocytoma (Grade II)
}

\author{
Sohrab Shahzadi ${ }^{1}$, Parisa Azimi ${ }^{1, *}$, Khosrow Parsa $^{2}$ \\ ${ }^{1}$ Department of Neurosurgery, Shahid-Beheshti University of Medical Science, Tehran, IR Iran \\ 2 Department of Neurosurgery, Firozgar Hospital, Tehran, IR Iran \\ * Corresponding author:Parisa Azimi, Department of Neurosurgery, Imam Hossein General Hospital, Tehran, IR Iran. Tel.: +98-2177558081, Fax: +98- \\ 2177558081, E-mail: parisa.azimi@gmail.com.
}

\begin{abstract}
A B S T R A C T
Background: Treatment of low-grade astrocytoma (WHO grade II) (LGA II) remains a challenge. There is limited information regarding the long-term effects of stereotactic brachytherapy (SBT) (temporary 125Iodine seeds) on patients with LGAII.

objectives: The purpose of this study was to evaluate disease control and survival after stereotactic brachytherapy in patients with circumscribed and relatively small size tumors.

Materials and Methods: A retrospective review of 29 patients, treated between 1991 and 2011, was conducted to evaluate survival, complications, and local disease control after stereotactic brachytherapy. They belonged to a larger group of 48 cases with low-grade gliomas, treated with stereotactic brachytherapy. The demographic and clinical characteristics in patients including age, sex, and survival time were extracted from records.

Results: Thirteen patients were male and 16 were female, with the median age of 29 years (range, 2.5 - 64 years). The median follow-up was 95 (range, 6 - 240) months. Based on Pignatti classification, 10 patients were at low- and 19 patients at high-risk. The median overall as well as progression-free survivals for patients were 135 months (95\% confidence interval: 76 - 194) and 96 months (95\% confidence interval:1 - 199), respectively. Five- and 10-year progression-free survivals were $41.4 \%$ and $34.5 \%$, respectively, and the 5 - and 10-year overall survivals were $65.5 \%$ and 44.8\%, respectively. Progression-free survival was not significantly higher in smaller size tumors $(\mathrm{P}=0.224)$, nor for spherical versus nonspherical tumors $(\mathrm{P}=0.307)$. There was no treatment-related morbidity after stereotactic brachytherapy, and no radiogenic complications occurred during the follow-up period. Mortality due to tumor progression occurred in 4 patients (14\%), and 11 patients were alive at the last follow-up.

Conclusions: The stereotactic brachytherapy for patients with circumscribed and relatively small size tumors appears to be a safe, feasible, and minimally-invasive treatment.
\end{abstract}

Keywords: Survival; Long-Term; Astrocytoma; Brachytherapy

Copyright (@) 2013, Iranian Red Crescent Medical Journal; Published by Kowsar Corp.

\section{Background}

Low-grade gliomas (LGGs) (World Health Organization grade I and II) are slow growing brain tumors which constitute about one-sixth of glioma brain tumors (1). According to the World Health Organization (WHO) data, lowgrade astrocytomas (LGAs II) (Grade II) comprise 15 to $25 \%$ of LGGs, constituting only 8\% of recorded astrocytomas.

For most patients with LGAs, there is no clear causal factor, and the current research indicates that the environment might play a role in their origin. Although LGA II was traditionally considered as benign, it could behave aggressively and undergo anaplastic transformation within 5 years in approximately half of the patients $(2,3)$. Malignant trans-

-Article type: Research Article; Received: 01 Feb 2012, Revised: 16 Jun 2012, Accepted: 24 Sep 2012; DOI: 10.5812/ircmj.4322

Implication for health policy/practice/research/medical education:

This study was to evaluate disease control and survival after stereotactic brachytherapy in patients with circumscribed and relatively small size tumors.

Please cite this paper as:

Shahzadi S, Azimi P, Parsa Kh. Long-Term Results of Stereotactic Brachytherapy (Temporary 125Iodine Seeds) for the Treatment of Low-Grade Astrocytoma (Grade II). Iran Red Crescent Med J. 2013;15(1):49-57. DOI:10.5812/ircmj.4322

Copyright @ 2013, Iranian Red Crescent Medical Journal; Published by Kowsar Corp.

This is an Open Access article distributed under the terms of the Creative Commons Attribution License (http://creativecommons.org/licenses/by/3.0), which permits unrestricted use, distribution, and reproduction in any medium, provided the original work is properly cited. 
formation occurs in $36-86 \%$ (4) of LGG patients, in $90 \%$ of adults $(5,6)$, and less than $10 \%$ of children with LGA II (7). Pignatti and colleagues ${ }^{8}$ have classified LGG patients based on 5 criteria: age $\geq 40$ years, astrocytoma histology, largest dimension of tumor $\geq 6 \mathrm{~cm}$, tumor crossing the midline, and the presence of neurologic deficit before resection which are unfavorable prognostic factors (8). Patients with up to two of these findings are considered as low-risk, while patients with three or more are identified as high-risk (8).

Management, treatment, and survival of patients with LGA II are one of the challenges for a neurosurgeon (9). Different treatment options are available for LGA II at the present. Although surgery, radiation therapy (RT), stereotactic radiosurgery (SRS), and chemotherapy might be used to treat LGG, either separately or in combination (9), intraoperative implantation of ${ }^{125}$ Iodine seeds for brachytherapy (i.e. interstitial and intracystic) is also possible (10). Brachytherapy has a long history in the treatment of central nervous system tumors with the first treatment being carried out by Hirsch et al. in 1912 (11), and stereotactic (interstitial) ${ }^{125}$ Iodine was first used in brachytherapy of LGGs, in 1984 by Gutin et al. (9) Using temporary or permanent implants yet remain controversial (9). While some investigators advocate using permanent seeds (12), others prefer to use temporary implants (13).

Stereotactically guided interstitial therapy is a treatment option for gliomas (14). Modern imaging systems for tumor localization $(15,16)$ and three-dimensional radiation treatment planning programs to determine optimal access points and management of dose distribution $(9,17)$ have the potential to improve the stereotactic brachytherapy (SBT) results. The present retrospective study reports our experience with stereotactic (interstitial) ${ }^{125}$ Iodine brachytherapy (SBT) in patients with LGA II. Survival, complications, tumor control, and 20 years outcomes among our patients are evaluated.

\section{Objectives}

The purpose of this study was to evaluate disease control and survival after stereotactic brachytherapy for patients with circumscribed and relatively small size tumors.

\section{Materials and Methods}

\subsection{Patients and Data Collection}

During a 20-year (January 1991-January 2011) period, 48 patients with circumscribed and relatively small size LGGs were treated in our department with stereotactic implantation of ${ }^{125}$ Iodine seeds, of which 29 were eligible to enter this study (patients with astrocytoma grade 2). Cases with oligodendroglioma, mixed glioma, and astrocytomas (all with Grade I) were excluded to avoid selection bias. Patients were selected for SBT protocol if they fulfilled at least one of the criteria listed in Figure 1. The criteria were set based on previous experience in our clinic and National Comprehensive Cancer Network Clinical Practice Guidelines in Oncology (18). In summary, patients were treated with SBT if: A. Maximal safe resection of their tumor was not feasible; B. Their tumor's histology was needed; and C. Local recurrence occurred after treatment with SRS, RT, or surgery. Eleven patients (38\%) had undergone surgery with partial resection before SBT, and in 18 cases (62\%), maximal safe resection was not feasible. In 15 out of 29 cases (51.7\%), SBT was offered primarily because a stereotactic biopsy was necessary. Additional selection criteria in favor of SBT and against SRS included tumor volume $\geq 14 \mathrm{cc}$ in 8 patients $(27 \%$ ), and local tumor recurrence after SRS and/or RT in 3 patients (10\%).

The risk assessment for patients was based on classification by Pignatti and colleagues (8). Interstitial temporary SBT was performed utilizing photon radiation of ${ }^{125} \mathrm{Io}$ dine seeds (model 6702, Medi-Physics Inc., Amersham Health Care, USA, measuring $4.5 \times 0.8 \mathrm{~mm}$, photon energy spectrum $27-35 \mathrm{keV}$ ).

\subsection{Treatment Planning and Surgical Procedure}

Access and dose planning were performed on the basis of CT images (2 mm slice thickness, $290 \mathrm{~mm}$ field of view (FOV), 512 matrix) with a stereotactic localizer (19). Using Stereotactic Treatment Planning "STP” (Fischer Leibinger, Freiburg, Germany) (20), a 3D multiplanar treatment planning system, a protocol was designed to deliver optimum dose to the target volume ( Figure 2 ). The specified doses corresponded to the TG43 protocol (21). Prescribed cumulative reference dose on the surface of tumor was 60 Gy. The median D90 (defined by the dose that covers 90\% of the tumor volume) and the V150 were $57.2 \mathrm{~Gy}$ (range: $44.3-79.2 \mathrm{~Gy}$ ) and $57.8 \%$, respectively. All patients were operated on using ${ }^{125}$ Iodine seeds placed in standard catheters under general anaesthesia, with the patient's head fixed in a modified Riechert - Mundinger (RM) stereotaxic frame (19). Stereotactic ${ }^{125}$ Iodine seed implantation was performed immediately after histological confirmation of LGG in biopsy. The correct positioning of the seeds was confirmed on post-implant CT or MR data sets by fusion with the treatment plan. In most cases, one seed was inserted, but two seeds were implanted in 7 patients in whom the sizes and shapes of tumors made it necessary based on treatment planning (TP) mentioned above. Biopsies were taken along a trajectory representative of the tumor at least one time before and after the procedure as needed. The average amount of tissue per biopsy specimen was $1 \mathrm{~mm}^{3}$. Hospitalization time was usually $3-4$ days for biopsy and seed implantation, and one more day to remove the seed catheter(s).

\subsection{Follow-up}

The reference points for this study were the date of initial SBT procedure. The primary end-points for the 


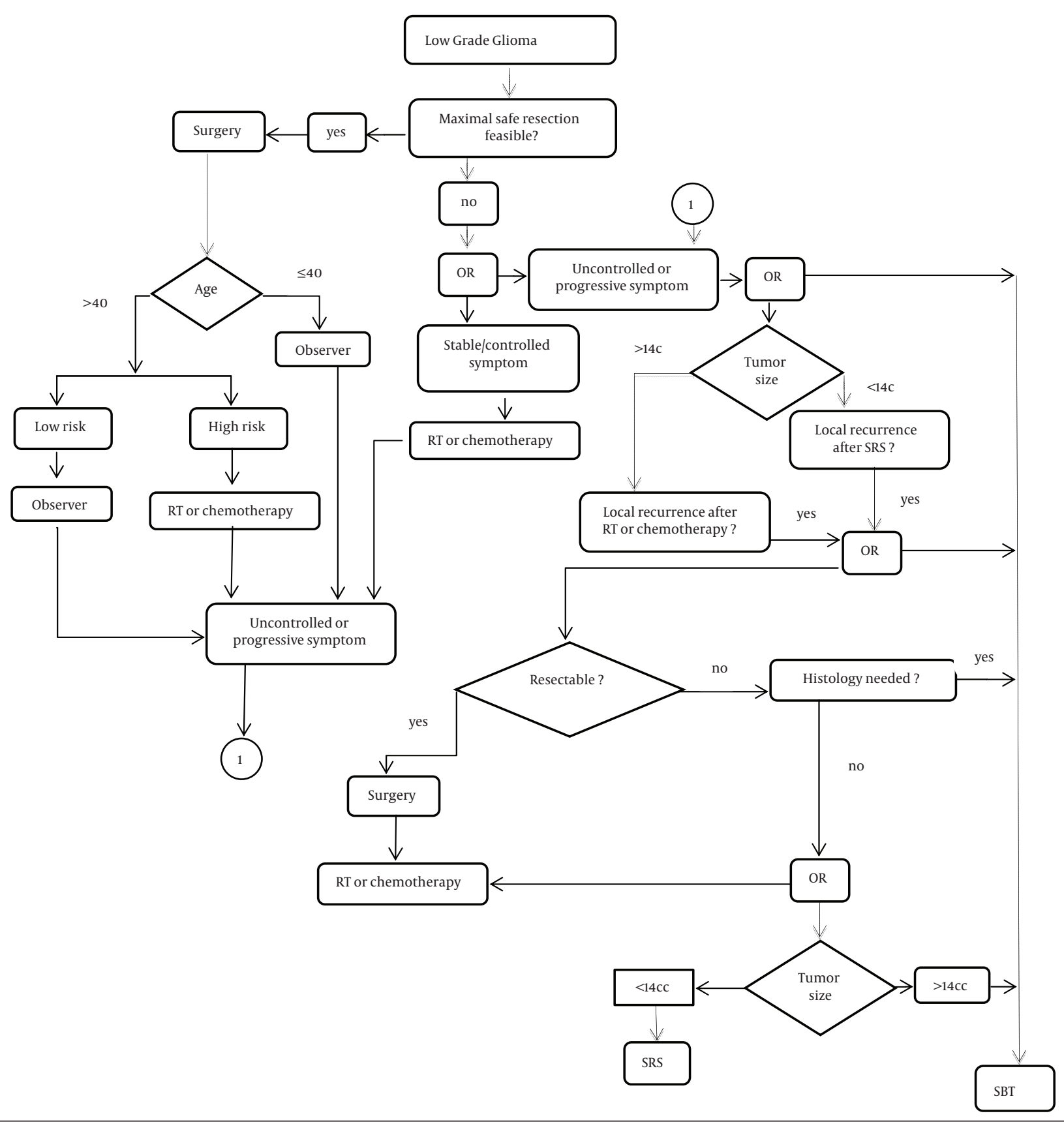

Figure 1. The algorithm shows a decision process for treatment selection in low-grade gliomas. SBT, stereotactic (Interstitial) 125Iodine brachytherapy; SRS, Stereotactic Radiosurgery; RT, Radiation Therapy

statistical analysis were overall survival (OS) which was defined as the time from study entry to death from any cause; progression-free survival (PFS) was defined as the minimum time from study entry to disease progression, disease relapse, or death from any cause. The follow-up period for all patients was 6 months to 20 years during which the PFS and OS for all patients were recorded. Side effects and changes in imaging after SBT were also observed during the follow-up period.

\subsection{Statistical Analysis}

Kaplan-Meier survival curves were generated for each study variable using PASW Statistics 18, version 18 (SPSS, Inc., 2009, Chicago, IL). Survival rates for 5, 10, and 20 years were calculated along with their corresponding standard error (SE). Data are given as mean, median, and SD. Values of $\mathrm{P} \leq 0.05$ were considered statistically significant. 


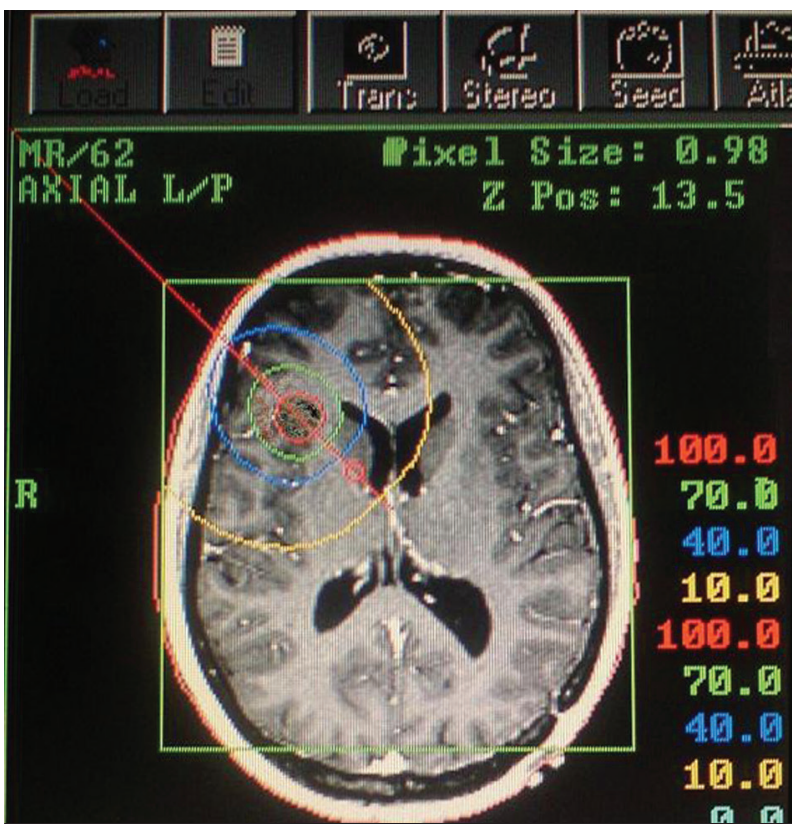

Figure 2. An Implant Planning for a Right Frontal Low-Grade Glioma Shows the Catheter Trajectory

\subsection{Ethics}

All patients gave their informed consent after receiving both written and oral information about the project. The study was approved by the Ethics Committee of Shahid Beheshti University of Medical Sciences, Tehran, Iran.

\section{Results}

Patient characteristics and outcomes are summarized in Table 1 and Table 2 , respectively.

\subsection{Survival}

The median FPS and OS for patients was 96 months (95\% confidence interval: 1 - 199), and 135 months (95\% confidence interval: 76 -194) ( Figure $3, A$ and B), respectively. Five-year (10 - year) PFS was $56 \%$ (47\%), and 5-year (10 - year) OS was $81 \%$ (56\%), respectively. Progression-free survival was not significantly higher for smaller tumor $(P=0.224)$, nor for spherical versus non-spherical tumors $(\mathrm{P}=0.307)$. Of 11 patients who were alive at the last follow-up, no evidence of tumor recurrence and radiation encephalopathy was observed, and 4 (14\%) patients survived over 17 years.

Table 1. Patient Characteristics $(n=29)$

\begin{tabular}{|c|c|c|c|}
\hline & No. of Patients & Percentage (\%) & Median ( \pm SD), range \\
\hline Age, years & & & $29 \pm 15.6(2.5-64)$ years \\
\hline Gender (Female/Male) & $16 / 13$ & $55 / 45$ & \\
\hline Follow up time & & & $95 \pm 77(6-240)$ months \\
\hline KPS Preoperative & & & $93.45 \pm 9.36(70-100)$ \\
\hline Previous surgery & 11 & 28.9 & \\
\hline Previous chemotherapy & 0 & 0 & \\
\hline Previous radiotherapy & 2 & 6.9 & \\
\hline Previous radiosurgery & 1 & 3.4 & \\
\hline Neurological Symptoms (Yes/No) & $18 / 11$ & $62 / 38$ & \\
\hline High/low-risk patients & $10 / 19$ & $35 / 65$ & \\
\hline \multicolumn{4}{|l|}{ Tumor site } \\
\hline Central (hypothalamic/thalamic/optic) & 10 & 35 & \\
\hline Cerebral hemisphere & 16 & 55 & \\
\hline Posterior fossa & 3 & 10 & \\
\hline \multicolumn{4}{|l|}{ Histologic type at diagnosis } \\
\hline Astrocytoma II & 29 & 100 & \\
\hline \multicolumn{4}{|l|}{ Tumor shape } \\
\hline Spherical/non-spherical & $19 / 10$ & $65 / 35$ & \\
\hline Tumor volume (cc) & & & $13.9 \pm 8.8(4.2-33.6) \mathrm{cc}$ \\
\hline Source dwell time & & & $97 \pm 24.9(20-120)$ days \\
\hline Energy dose rate & & & $8.32 \pm 1.58 \mathrm{cGy} / \mathrm{h}$ \\
\hline Dosage at the tumor margin & & & $60 \pm 1.03(50-60) \mathrm{Gy}$ \\
\hline Activity of each seed at implantation time & & & $9.2 \pm 11.2(5-16) \mathrm{mci}$ \\
\hline
\end{tabular}




\begin{tabular}{llll}
\hline Table 2. Patient Outcomes $(\mathrm{n}=29)$ & & & \\
\hline & No. of Patients & Percentage $(\%)$ & Median ( \pm SD), range \\
\hline $\begin{array}{l}\text { KPS at last follow-up } \\
\text { Tumor Volume at Final Follow-up }\end{array}$ & & & $95.52 \pm 10.2(80-100)$ \\
\hline $\begin{array}{l}\text { Increase/Stable or decrease } \\
\text { Survival }\end{array}$ & $6 / 23$ & $21 / 79$ & \\
\hline $\begin{array}{l}\text { Overall survival(OS) } \\
\text { Progression free survival(PFS) }\end{array}$ & & & $135(76-194)$ months \\
\hline $\begin{array}{l}\text { Cause of death } \\
\text { Neurological death }\end{array}$ & 3 & & $96(1-199)$ months \\
\hline Systemic death & 12 & 10 & \\
Information missing & 3 & 41 & \\
\hline Living patients & 11 & 10 & \\
\hline
\end{tabular}

No significant improvement in 5-year PFS or 5-year OS was seen when comparing patients receiving preoperative RT with those with no preoperative RT. A preoperative CT scan from one patient undergoing SBT treatment and the postoperative MRI from the same patient nineteen years later is present in Figure 4.

At the time of analysis, 11 out of 29 patients (38\%) were alive and well: 6 patients had SBT as primary treatment, 3 had SBT after a surgical resection, and 2 had SBT for a recurrence after previous external beam RT. Four patients (14\%) died from tumor progression: three died from neurological complications, and one from systemic complications associated with tumor recurrence. Eleven patients died with other non-tumor related systemic causes. Only four patients died due to the complications of tumor progression in our study; so, no statistical comparison of survival based on different methods was possible.

\subsection{Local Tumor Control}

A local tumor control rate of $86 \%$ was achieved at last follow-up. Local growth of tumor after SBT was observed in 2 cases at 13 and 28 months, and SBT was repeated.

\subsection{Complications}

No serious neurological complications followed the SBT, and the quality of life was not seriously affected by the treatment in other patients. In 10 out of 11 patients who were alive, function was estimated to be good or excellent based on Karnofsky performance status (KPS). In one patient with poor function, the cause was found to be both treatment-and disease-related.

\section{Discussion}

To our knowledge, several studies have reported the long-term outcome of SBT and other treatment options for LGGs in the English literature ( Table 1 ) (14, 22-31). Our findings were promising in treating patients with
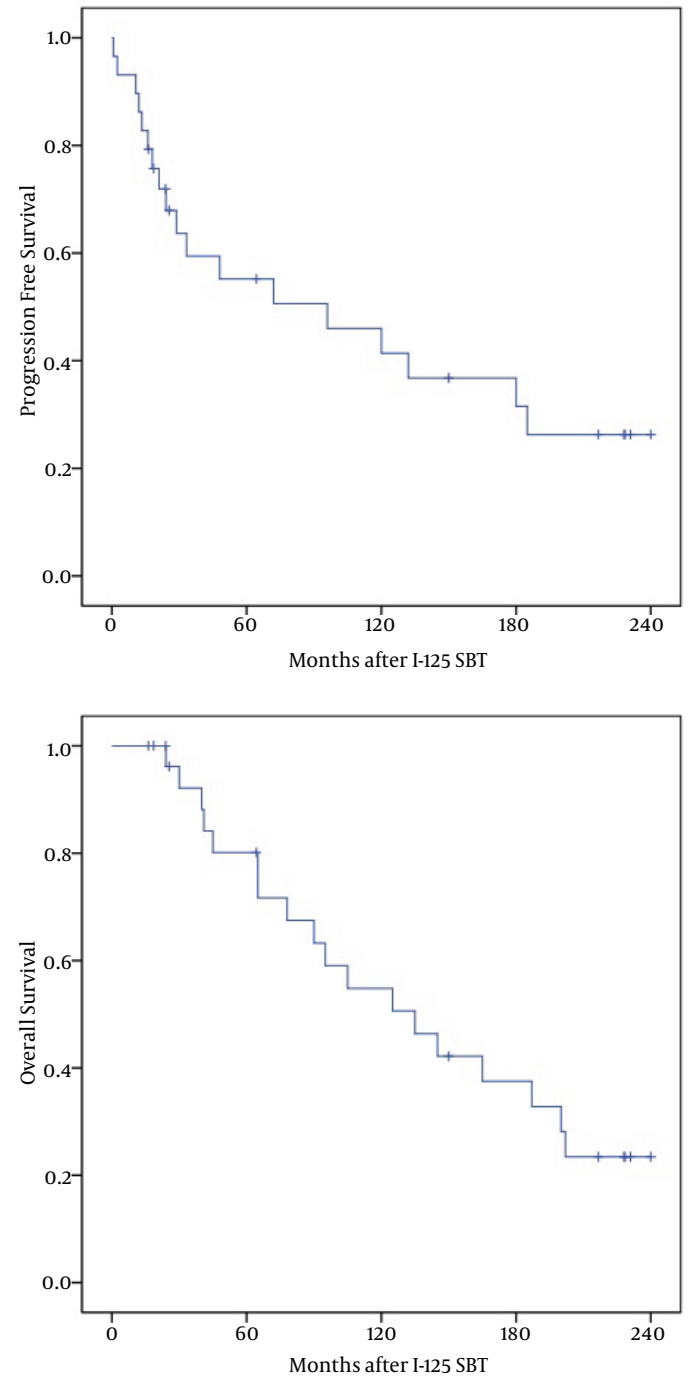

Figure 3. Kaplan-Meier Survival Curves for Patients Treated with Stereotactic 125Iodine Brachytherapy for Low Grade Astrocytoma Grade II. A. Progression Free Survival; B. Overall Survival. Median OS and FPS was 135 and 96 Months, Respectively 


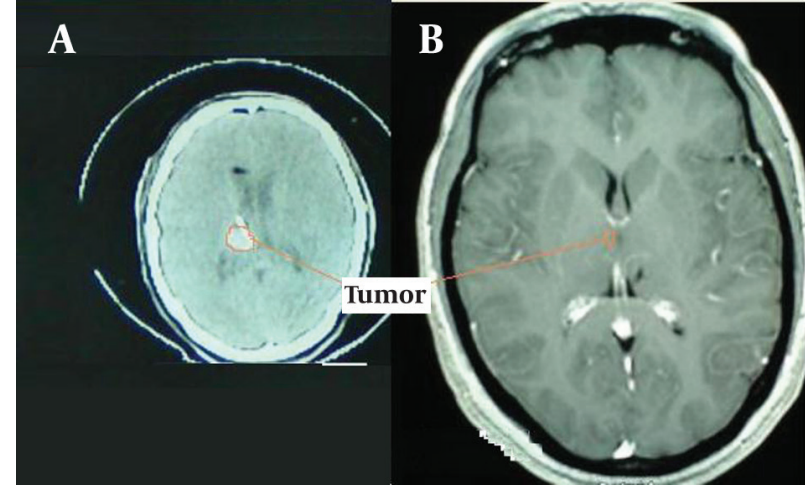

Figure 4. A Preoperative CT Scan from One Patient Undergoing SBT Treatment (B). Postoperative MRI from the Same Patient Nineteen Years Later $(\mathrm{A})$

circumscribed and relatively small size LGGs. However, the favorable results could possibly be explained by selection of patients with well-established favorable prognostic factors such as younger age (mean: 29 years), almost perfect clinical condition (KPS mean: 93.45), and small tumors (mean: $13.9 \mathrm{cc}$ ). These patients might probably do equally well with external beam radiotherapy alone or in combination with surgery $(8,24,27)$. The five-year survival rates of brachytherapy using SBT method have been reported to be between $54.6 \%$ to $97 \%(14,22,23,30$, 31 ), which is in line with our findings. A direct comparison between the outcomes of different methods used by us and other studies might be misleading, as the baseline characteristics of patients are different. As an example, the better outcomes reported by Korinthenberg et al. (31) and Wisoff et al. (28), might be due to the presence of younger patients in their study compared to our study. In a study conducted by Ahmadi et al. (25), only $46 \%$ of patients had pathology of astrocytoma, which might contribute to better 5 and 10 years survival rates reported by them. In the study by Kevin et al., only $7 \%$ of patients had grade II astrocytoma and 55\% had grade I with a mean age of 8.7 years for patients, which might again contribute to their good reported results. Bauman et al. (26) reported a long-term (20 years) treatment of supratentorial LGGs with surgery, RT and chemotherapy, either separately or in combination, with a median follow-up of 105 months. The median PFS was 61 months (95\% confidence interval: 53-77), and the median OS was 118 months (95\% confidence interval: 93 -129). In a retrospective analysis of 250 patients with WHO grade II astrocytomas treated with either permanent or temporary ${ }^{125}$ Iodine implants, Kreth et al.(22) reported a 5-year survival rate of $61 \%$. This study used both temporary and permanent implants. Using temporary or permanent implants are one of the controversies of brachytherapy application in central nervous system tumors (9). However, better outcomes have been reported by Schnell et al. (14). It has been suggested that these findings might be related to the effects of selection, the relatively short follow-up period, and/or the benefit of combined treatment approach (14).

In the subsequent study, Kreth et al. (32) also suggested the SBT option to be associated with prolonged survival (10-year survival rate in the range of $84 \%$ and low-risk in patients with small tumor volumes). Another study by Central Brain Tumor Registry of the United States (CBTRUS) reported that grade II oligodendrogliomas had much better 5-year survival rate (70\%) compared to mixed gliomas (56\%) and astrocytomas (37\%) (33). Another factor to consider while comparing outcomes is the fact that patients with more superficial tumors have undergone radiotherapy, and patients with more deeply seated tumors have been candidates for SBT method. At the time of analysis, 11 out of 29 patients (38\%) were alive and well: 6 patients had SBT as primary treatment, 3 had SBT after a surgical resection, and 2 had SBT for a recurrence after previous external beam RT. The other information is provided in Table 3. Due to limited number of patients with prior radiotherapy, we could not compare these survival rates.

The OS and PFS of LGA II patients with astrocytoma histology are worse than the rest of the LGG patients (34). In LGG patients, the factors consistently known to be associated with improved survival include younger age (34, 35), higher KPS score (36), pathology (34), size of tumor $(34,37)$, postoperative RT, (17) tumor location $(14,38)$ (eloquent areas and deep-seated lesions are worse than other areas), and gross total resection (GTR) $(25,38)$. In the present study, we were not able to show any difference in OS or PFS based on these factors. The indiscrimination might be related to the small number of patients, or to the fact that all patients received SBT, after entry to the study and all had uniform astrocytoma (grade II) histology. Tacke et al. (28) reported the incidence of vasculopathy in children with hypothalamic/chiasmatic gliomas treated with SBT, but this complication was not observed in our study. Older reports have found a mortality rate of 3.3\% to $6.5 \%$ after surgical resection of low-grade astrocytomas, but the benefit of radical surgical resection in the survival of patients with astrocytomas remained controversial (39). In a recent report by Chang et al. (40), the survival rate in the group undergoing surgery for LGG in eloquent areas of the brain using mapping - guided resection have been reported for 5-year OS and 5-year PFS as $86 \%$ and $62 \%$, respectively, which demonstrated better outcomes when more modern surgical techniques were used.

In our study, the mortality due to tumor progression occurred in 4 patients (14\%). The minimally invasive nature of SBT and the overall postoperative status in our cases would indicate that quality of life was not seriously affected by the treatment. During the analysis, 18 out of 29 patients (62\%) died: 9 patients had SBT as primary treatment, 1 had SBT after a SRS, and 8 had SBT for a recurrence after previous surgical resection. 


\begin{tabular}{|c|c|c|c|c|c|c|c|c|c|c|}
\hline \multirow{2}{*}{$\begin{array}{l}\text { Author } \\
\text { (ref.) }\end{array}$} & \multirow[t]{2}{*}{ Year } & \multirow[t]{2}{*}{ LGGS } & \multirow{2}{*}{$\begin{array}{l}\text { No. of } \\
\text { Patients }\end{array}$} & \multirow[t]{2}{*}{ Treatment } & \multicolumn{2}{|l|}{ SBT } & \multirow[t]{2}{*}{$5 / 10$ - year } & \multirow[t]{2}{*}{$5 / 10$ - year } & \multirow[t]{2}{*}{$15 / 20$ - yea } & \multirow[t]{2}{*}{$15 / 20$ - year } \\
\hline & & & & & $\begin{array}{l}\text { Tempo- } \\
\text { rary }\end{array}$ & $\begin{array}{l}\text { Perma- } \\
\text { nent }\end{array}$ & & & & \\
\hline $\begin{array}{l}\text { Kreth et } \\
\text { al.(22) }\end{array}$ & 1995 & $\begin{array}{l}\text { Astrocyto- } \\
\text { mas (II) }\end{array}$ & 250 & SBT & + & + & OS (\%) & PFS (\%) & OS (\%) & PFS (\%) \\
\hline $\begin{array}{l}\text { Mehrkens } \\
\text { et al. (23) }\end{array}$ & 2004 & $\begin{array}{l}\text { Astrocyto- } \\
\text { mas of the } \\
\text { Insula of } \\
\text { Reil (II) }\end{array}$ & 55 & SBT & + & + & $61 / 51$ & NR & NR & NR \\
\hline $\begin{array}{l}\text { Van den et } \\
\text { al.(24) }\end{array}$ & 2006 & LGGs (II) & 157 & RT & - & - & $54.6 / 28.4$ & $40.7 / 20.2$ & NR & NR \\
\hline $\begin{array}{l}\text { Schnell et } \\
\text { al.(14) }\end{array}$ & 2008 & LGGs (II) & 31 & $\mathrm{~S}+\mathrm{SBT}$ & + & - & $66 / N R$ & $35 / N R$ & NR & NR \\
\hline $\begin{array}{l}\text { Ahmadi et } \\
\text { al. (25) }\end{array}$ & 2009 & $\begin{array}{l}\text { Supraten- } \\
\text { torial LGGs } \\
\text { (II) }\end{array}$ & 130 & $\begin{array}{l}\text { S+Adjuvant } \\
\text { treatment }\end{array}$ & - & - & $93 / \mathrm{NR}$ & $62 / N R$ & NR & NR \\
\hline $\begin{array}{l}\text { Bauman, } \\
\text { et al. (26) }\end{array}$ & 2009 & $\begin{array}{l}\text { Supraten- } \\
\text { torial LGGs } \\
\text { (II) }\end{array}$ & 145 & $\begin{array}{l}\text { RT or } \mathrm{S} \text { or } \mathrm{Ch} \text {, ei- } \\
\text { ther separately } \\
\text { or in combina- } \\
\text { tion }\end{array}$ & & - & $85 / 55$ & $41 / 11$ & $36 / 28$ & $0 / 0$ \\
\hline $\begin{array}{l}\text { Schomas } \\
\text { et al. (27) }\end{array}$ & 2009 & LGGs (II) & 314 & $\begin{array}{l}\text { RT or S or Ch, ei- } \\
\text { ther separately } \\
\text { or in combina- } \\
\text { tion }\end{array}$ & & - & $\mathrm{NR} / 48$ & $\mathrm{NR} / 18$ & $\mathrm{NR} / 22$ & $\mathrm{NR} / \mathrm{O}$ \\
\hline $\begin{array}{l}\text { Wisoff et } \\
\text { al. (28) }\end{array}$ & 2011 & LGG (I,II) & 518 & $\begin{array}{l}\text { S+ Adjuvant } \\
\text { treatment }\end{array}$ & - & - & $58 / 36$ & $50 / 27$ & $23 / 17$ & $17 / 15$ \\
\hline $\begin{array}{l}\text { Kevin et } \\
\text { al.(29) }\end{array}$ & 2011 & LGG (I,II) & 181 & $\begin{array}{l}\text { RT or S or Ch, ei- } \\
\text { ther separately } \\
\text { or in combina- } \\
\text { tion }\end{array}$ & - & - & $97 / 95$ & 79/73 & NR & NR \\
\hline $\begin{array}{l}\text { Suchorska } \\
\text { et al. (30) }\end{array}$ & 2011 & LGGs (II) & 95 & SBT after S. & + & + & $95 / 90$ & $70 / 65$ & $81 / N R$ & $60 / \mathrm{NR}$ \\
\hline $\begin{array}{l}\text { Ko- } \\
\text { rinthen- } \\
\text { berg et al. } \\
(31)\end{array}$ & 2011 & LGGs (II) & 94 & SBT & + & - & NR & $43.4 / 10.7$ & NR & NR \\
\hline $\begin{array}{l}\text { Present } \\
\text { study }\end{array}$ & 2011 & $\begin{array}{l}\text { Astrocy- } \\
\text { toma (II) }\end{array}$ & 29 & $\begin{array}{l}\text { After RT or S, ei- } \\
\text { ther separately } \\
\text { or in combi- } \\
\text { nation, SBT } \\
\text { performed }\end{array}$ & + & - & $97 / 92$ & $59 / 38$ & NR & NR \\
\hline
\end{tabular}

There was no sufficient data available to compare outcome measurements after SRS with those after brachytherapy. Considering the fact that a proper guideline was not suggested to choose a treatment method for these patients, we tried to devise such a guideline ( Figure 1 ). We feel that because of our study limitations, this guideline is still primitive and needs to be re-evaluated and modified based on future research efforts. For example, we feel a need to separate guidelines for children and adults, but our data were not suitable to devise.

\subsection{Limitations and strength of the present study}

There are several principle weaknesses in this study. The first is retrospective nature and inherent limitations of this methodology. Second is the comparatively small number of patients. Although, this is the largest single- institution series of LGA II reported in 29 patients treated with SBT in Iran, it remains a small number for statistical comparison. Our study also suffers from some other limitations like different treatments for patients prior to entering our study, and the variation in tumor location.

Finally, due to different patients' baseline characteristics, it is very difficult to compare these results with that of primary surgery, with or without external beam radiotherapy, or with more conventional treatments of recurrent LGG. Even compared to other brain tumors, SBT series needs some reservation. However, the current study had several strengths including a 20-year fallow-up survival analysis, using temporary ${ }^{125}$ Iodine seed as SBT, and providing a flow chart for the first time as a guideline for SBT. The SBT for patients with circumscribed and relatively small size tumors appears to be a safe, feasible, and mini- 
mally-invasive treatment.

\section{Acknowledgements}

The authors thank Dr. Gite Irvanlo, neuropathologist; Dr. Gholamreza Bakhshandehpour, neuroradiologist; Dr. Farhad Samii , radiation- oncologist; Dr. Hassanali Nedaei, radiation-physicist, and the staff of the neurosurgery unit of Shohada Tajrish Medical Center, Tehran, Iran.

\section{Authors' Contribution}

All authors were involved in designing of the study, data collection and analysis, interpretation of results, and manuscript preparation. SS and PA prepared the first draft of paper and provided the final manuscript. All authors read and approved the final manuscript.

\section{Financial Disclosure}

None.

\section{Funding/Support}

None declared.

\section{References}

1. Howlader N, Noone A, Krapcho M, Neyman N, Aminou R, Waldron W, et al. SEER Cancer Statistics Review, 1975-2008. Bethesda, MD: National Cancer Institute; 2011. Also available online Last accessed December. 2011;1.

2. Piepmeier J, Christopher S, Spencer D, Byrne T, Kim J, Knisel JP, et al. Variations in the natural history and survival of patients with supratentorial low-grade astrocytomas. Neurosurgery. 1996;38(5):872-8;

3. Afra D, Osztie E, Sipos L, Vitanovics D. Preoperative history and postoperative survival of supratentorial low-grade astrocytomas. Br J Neurosurg. 1999;13(3):299-305.

4. Kortmann RD, Jeremic B, Weller M, Lutterbach J, Paulsen F, Bamberg M. Immediate postoperative radiotherapy or "watch and wait" in the management of adult low-grade glioma? Strahlenther Onkol. 2004;180(7):408-18.

5. Vertosick FT, Jr., Selker RG, Arena VC. Survival of patients with well-differentiated astrocytomas diagnosed in the era of computed tomography. Neurosurgery. 1991;28(4):496-501.

6. McCormack BM, Miller DC, Budzilovich GN, Voorhees GJ, Ransohoff J. Treatment and survival of low-grade astrocytoma in adults-1977-1988. Neurosurgery. 1992;31(4):636-42;

7. Broniscer A, Baker SJ, West AN, Fraser MM, Proko E, Kocak M, et al. Clinical and molecular characteristics of malignant transformation of low-grade glioma in children.J Clin Oncol. 2007;25(6):682-

8. Pignatti F, van den Bent M, Curran D, Debruyne C, Sylvester R, Therasse P, et al. Prognostic factors for survival in adult patient with cerebral low-grade glioma.J Clin Oncol. 2002;20(8):2076-84.

9. Liu BL, Cheng JX, Zhang X, Zhang W. Controversies concerning the application of brachytherapy in central nervous system tumors. J Cancer Res Clin Oncol. 2010;136(2):173-85.

10. Brown PD. Low-grade gliomas: the debate continues. Curr Oncol Rep. 2006;8(1):71-7.

11. Bernstein M, Gutin PH. Interstitial irradiation of brain tumors: a review. Neurosurgery. 1981;9(6):741-50.

12. McDermott MW, Berger MS, Kunwar S, Parsa AT, Sneed PK, Larson DA. Stereotactic radiosurgery and interstitial brachytherapy for glial neoplasms. J Neurooncol. 2004;69(1-3):83-100.

13. Etou A, Mundinger F, Mohadjer M, Birg W. Stereotactic interstitial irradiation of diencephalic tumors with iridium 192 and iodine 125: 10 years follow-up and comparison with other treatments. Childs Nerv Syst.1989;5(3):140-3.

14. Schnell O, Scholler K, Ruge M, Siefert A, Tonn JC, Kreth FW. Surgica resection plus stereotactic 125 I brachytherapy in adult patients with eloquently located supratentorial WHO grade II glioma feasibility and outcome of a combined local treatment concept J Neurol. 2008;255(10):1495-502.

15. Alexander E, 3rd, Kooy HM, van Herk M, Schwartz M, Barnes PD, Tarbell N, et al. Magnetic resonance image-directed stereotactic neurosurgery: use of image fusion with computerized tomography to enhance spatial accuracy.J Neurosurg. 1995;83(2):271-6.

16. Herholz K, Pietrzyk U, Voges J, Schroder R, Halber M, Treuer H, et al. Correlation of glucose consumption and tumor cell density in astrocytomas. A stereotactic PET study.J Neurosurg. 1993;79(6):853-8.

17. Julow J, Viola A, Major T, Valalik I, Sagi S, Mangel L, et al. Iodine-125 brachytherapy of brain stem tumors. Strahlenther Onkol. 2004;180(7):449-54.

18. National Comprehensive Cancer Network (NCCN). Clinical Practice Guidelines in Oncology ${ }^{\mathrm{TM}}$ for Central Nervous System Cancers. Adult low- grade infiltrative supratentorial Astrocytoma/ Oligodendroglioma. Version 2. 2011 [updated 2011; cited]; Available from: http://www.nccn.org/professionals/physician_gls/f_guidelines.asp.

19. Sturm V, Pastyr O, Schlegel W, Scharfenberg H, Zabel HJ, Netzeband G, et al. Stereotactic computer tomography with a modified Riechert-Mundinger device as the basis for integrated stereotactic neuroradiological investigations. Acta neurochirurgica. 1983;68(1):11-7.

20. Zamorano L, Dujovny M, Malik G, Yakar D, Mehta B. Multiplanar CT guided stereotaxis and 125I interstitial radiotherapy. Image-guided tumor volume assessment, planning, dosimetric calculations, stereotactic biopsy and implantation of removable catheters. App Neurophysiol.1987;50(1-6):281-6.

21. Nath R, Anderson LL, Luxton G, Weaver KA, Williamson JF, Meigooni AS. Dosimetry of interstitial brachytherapy sources: recommendations of the AAPM Radiation Therapy Committee Task Group No. 43. American Association of Physicists in Medicine. Med Phys. 1995;22(2):209-34.

22. Kreth FW, Faist M, Warnke PC, Rossner R, Volk B, Ostertag CB. Interstitial radiosurgery of low-grade gliomas. J Neurosurg. 1995;82(3):418-29.

23. Mehrkens JH, Kreth FW, Muacevic A, Ostertag CB. Long term course of WHO grade II astrocytomas of the Insula of Reil after I-125 interstitial irradiation.J Neurol. 2004;251(12):1455-64.

24. van den Bent MJ, Afra D, de Witte O, Ben Hassel M, Schraub S, Hoang-Xuan K, et al. Long-term efficacy of early versus delayed radiotherapy for low-grade astrocytoma and oligodendroglioma in adults: the EORTC 22845 randomised trial. Lancet. 2005;366(9490):985-90.

25. Ahmadi R, Dictus C, Hartmann C, Zurn O, Edler L, Hartmann M, et al. Long-term outcome and survival of surgically treated supratentorial low-grade glioma in adult patients. Acta Neurochi (Wien). 2009;151(11):1359-65.

26. Bauman G, Fisher B, Watling C, Cairncross JG, Macdonald D. Adult supratentorial low-grade glioma: long-term experience at a single institution. Int J Radiat Oncol Biol Phys. 2009;75(5):1401-7.

27. Schomas DA, Laack NN, Rao RD, Meyer FB, Shaw EG, O'Neill BP, et al Intracranial low-grade gliomas in adults: 30 -year experience with long-term follow-up at Mayo Clinic. Neuro Oncol.2009;11(4):437-45.

28. Wisoff JH, Sanford RA, Heier LA, Sposto R, Burger PC, Yates AJ, et al. Primary neurosurgery for pediatric low-grade gliomas: a prospective multi-institutional study from the Children's Oncology Group. Neurosurgery. 2011;68(6):1548-54;

29. Oh KS, Hung J, Robertson PL, Garton HJ, Muraszko KM, Sandler $\mathrm{HM}$, et al. Outcomes of multidisciplinary management in pediatric low-grade gliomas. Int J Radiat Oncol Biol Phys. 2011;81(4):e481-8.

30. Suchorska B, Ruge M, Treuer H, Sturm V, Voges J. Stereotactic brachytherapy of low-grade cerebral glioma after tumor resection. Neuro Oncol.2011;13(10):1133-42.

31. Korinthenberg R, Neuburger D, Trippel M, Ostertag C, Nikkhah G. Long-term results of brachytherapy with temporary iodine-125 seeds in children with low-grade gliomas. Int J Radiat Oncol Biol 
Phys. 2011;79(4):1131-8.

32. Kreth FW, Faist M, Grau S, Ostertag CB. Interstitial 125I radiosurgery of supratentorial de novo WHO Grade 2 astrocytoma and oligoastrocytoma in adults: long-term results and prognostic factors. Cancer. 2006;106(6):1372-81.

33. CBTRUS: Statistical report: Primary Brain Tumors in the United States,1995-1999. Chicago: Published by Central Brain Tumor Registry of the United States (CBTRUS). p.

34. Sanai N, Chang S, Berger MS. Low-grade gliomas in adults. J Neurosurg. 2011;115(5):948-65.

35. Shaw E, Arusell R, Scheithauer B, O'Fallon J, O'Neill B, Dinapoli R, et al. Prospective randomized trial of low-versus high-dose radiation therapy in adults with supratentorial low-grade glioma: initial report of a North Central Cancer Treatment Group/Radiation Therapy Oncology Group/Eastern Cooperative Oncology Group study.J Clin Oncol. 2002;20(9):2267-76.
36. Piepmeier J, Baehring JM. Surgical resection for patients with benign primary brain tumors and low grade gliomas. J Neurooncol. 2004;69(1-3):55-65.

37. Mason WP. Progress in clinical neurosciences: Advances in the management of low-grade gliomas. Can J Neurol Sci. 2005;32(1):1826.

38. Smith JS, Chang EF, Lamborn KR, Chang SM, Prados MD, Cha S, et al Role of extent of resection in the long-term outcome of low-grade hemispheric gliomas. J Clin Oncol. 2008;26(8):1338-45.

39. North CA, North RB, Epstein JA, Piantadosi S, Wharam MD. Lowgrade cerebral astrocytomas. Survival and quality of life after radiation therapy. Cancer.1990;66(1):6-14.

40. Chang EF, Clark A, Smith JS, Polley MY, Chang SM, Barbaro NM, et al. Functional mapping-guided resection of low-grade gliomas in eloquent areas of the brain: improvement of long-term survival. Clinical article. J Neurosurg. 2011;114(3):566-73. 